colleagues show, their techniques for recording large numbers of neurons in the primary visual cortex with fine spatial and temporal resolution inevitably drive new concepts of cortical function. Fortunately, discussions of the visual cortex do not dominate the book. Perhaps this is because the key themes that run through it are questions of what the neural code is, and how time is represented in the brain, and both questions apply equally well to the brains of creatures great and small. These two questions are also considered in virtuoso solos by Carl van Vreeswijk and Andreas Herz.

A prize for the wittiest title goes to Larry Abbott who asks: "Where are the switches on this thing?" He points out that the problem of self-regulated switching is solved for digital computers, which are the most complex machines we have built, but when it comes to the flow of information through a brain we know only that there are ways of biasing the flow by mechanisms such as neuromodulation or inhibition. Thus, with a motivation certain to warm the heart of every invertebrate physiologist, he recommends that we study any reasonable candidate mechanisms for switching in a brain.

Hilbert stated that " the importance of a scientific work can be measured by the number of previous publications it makes it superfluous to read". Answers to some of the questions raised here will no doubt make the literature reviews of most $\mathrm{PhD}$ theses shorter, but what will we really understand even if all 23 problems in systems neuroscience are solved? This is the most difficult question of all, and its answer has a significance that goes far beyond even the ambitious goal of understanding the workings of a brain. Hilbert's vision for mathematics was carved on his tombstone - " $\mathrm{Wir}$ müssen wissen, wir werden wissen" ("We must know, we shall know") - but for those who study brains, even if we must, will we? Kevan A. C. Martin is at the Institute of Neuroinformatics, ETH/University of Zurich, Winterthurerstrasse 190, Zurich 8057, Switzerland.

\title{
Seeking meaning in the void
}

The View from the Center of the Universe: Discovering Our Extraordinary Place in the Cosmos

by Joel R. Primack \& Nancy Ellen Abrams

Riverhead Books: 2006.400 pp. $\$ 25.95$

\section{Simon Singh}

The married couple of philosopher Nancy Ellen Abrams and cosmologist Joel R. Primack are uniquely placed to discuss how our understanding of the Universe affects how we perceive our role in it. The ancient creation myths provide comfort and meaning, but they are fantasies. In contrast, modern cosmology offers a glimpse of reality but leaves many people cold. In View from the Center of the Universe, Abrams and Primack challenge themselves to try and get the best of both world views.

In the distant past, we convinced ourselves that we had a special place in the Universe. Geographically we were at the centre of space, with everything revolving around us, and biologically we thought that humans were an exceptional creation. But as each century passed, we realized that we are less and less special. Today, we see ourselves as insignificant in the context of the whole Universe. The copernican revolution relegated and redefined Earth as just another planet, and made the Sun the hub of the Universe. Then astronomers showed that the Sun is not even at the centre of the Milky Way, and eventually it became clear that there are billions of other galaxies, which made Earth seem trivial.

The problem with becoming increasingly insignificant was appreciated as far back as the seventeenth century by the French philosopher Blaise Pascal: "I feel engulfed in the infinite immensity of spaces whereof I know nothing and which know nothing of me. I am terrified...The eternal silence of these infinite spaces alarms me."

The existence of dark matter only further relegated humanity, as Primack pointed out in 1984: "Yet another blow to anthropocentricity: not only is man not the center of the universe physically (as Copernicus showed) or biologically (as Darwin showed), it now appears that we and all that we see are not even made of the predominant variety of matter in the universe?"

But Abrams and Primack argue that humans still hold a central and special position in the Universe, perhaps not geographically but in many other ways. For example, we are special because we are made of the rarest material in the Universe, namely large atoms. Also, we live at a central time, because most nearby galaxies are past their violent youths but are not yet senescent. And we live at the midpoint of our planet's life, which is a few billion years old, and which has a few billion more years before it will be roasted by our Sun swelling into a red giant. And humans have a reasonably central size, roughly halfway between the smallest length scales $\left(10^{-33} \mathrm{~cm}\right)$ and the distance to the cosmic horizon $\left(10^{2 \mathrm{~cm}}\right)$.

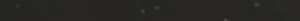


The book builds a good case as to why science should make us feel special, but sometimes the language, which wallows in mysticism, is irritating. We encounter the Pyramid of All Visible Matter, topped by the all-seeing eye, and parallels are drawn between cosmology and the Kabbalistic Order of Creation. There are also strange links made between physics and politics, such as the section that uses the laws of gravity and circular motion to explore the question of wealth distribution.

Abrams and Primack work hard to craft a view of science that might allow us to connect with the Universe, but it is risky to mix science with New Age jargon, particularly when there is a risk of confusing non-scientists. Films such as What the Bleep Do We Know? and dozens of pseudoscience books twist the bizarre laws of quantum physics to support all sorts of unscientific nonsense, and readers intrigued by such wacky notions will only have their ideas consolidated if they read about the Sovereign Eye, Abrams and Primack's mystical label for the conditions that give rise to intelligent life.
Although I have doubts about some of the language that the authors use to try and reconcile science and mysticism, I respect their efforts and some of their ideas. It is admirable that they have considered this problem worthy of discussion, even if they do not yet have all the answers. As Abrams and Primack point out, Einstein supposedly said: "Problems cannot be solved at the same level of awareness that created them."

Simon Singh is a science writer and the author of Fermat's Lost Theorem and Big Bang.

\section{Sympathy for the devil}

\section{Tasmanian Devil: A Unique and Threatened Animal \\ by David Owen \& David Pemberton \\ Natural History Museum/Allen \& Unwin: 2006.240 pp. $€ 12.99 / \$ 24.95$}

\section{Matthew J. Phillips}

Two representations have dominated public perceptions of the largest living marsupial carnivore, the Tasmanian devil. One is the voracious, hurricane-like innocent savage Taz of Looney Tunes cartoon fame. The other, familiar in nineteenth- and twentieth-century rural Tasmania, is the ferocious predator and scavenger that wantonly kills livestock - and perhaps even people, should they become immobilized in the wilderness at night. Devils can take prey nearly three times their size and eat more than a third of their body weight in a sitting. Even so, it is hard to imagine how this species, being only slightly larger than a fox terrier, could be so maligned in name and image.

In Tasmanian Devil, David Owen and David Pemberton delve into devil biology to convey the true nature of the beast once known to science as Sarcophilus satanicus (now S. harrisii). Fact and fiction are teased apart with sound science and tempered speculation. The devil's behaviour and physical appearance are explained in terms of its unique ecological position as a solitary nocturnal predator that relies heavily on communal scavenging. Its larger cousin, the thylacine (Thylacinus cynocephalus), is now extinct, so the devil's present ecological interactions and selection pressures may differ somewhat from those under which it evolved. This makes the authors' comparisons with placental analogues - the ratel (honey badger), wolverine and hyena - particularly instructive. Although a useful starting point for those with an academic interest in the Tasmanian devil, this book, with its well chosen photographs and historical illustrations, has far wider appeal.

The humour and tragedy associated with early European settlers' misunderstanding of the devil are neatly woven together, and the authors' arguments that the devil is not a rural

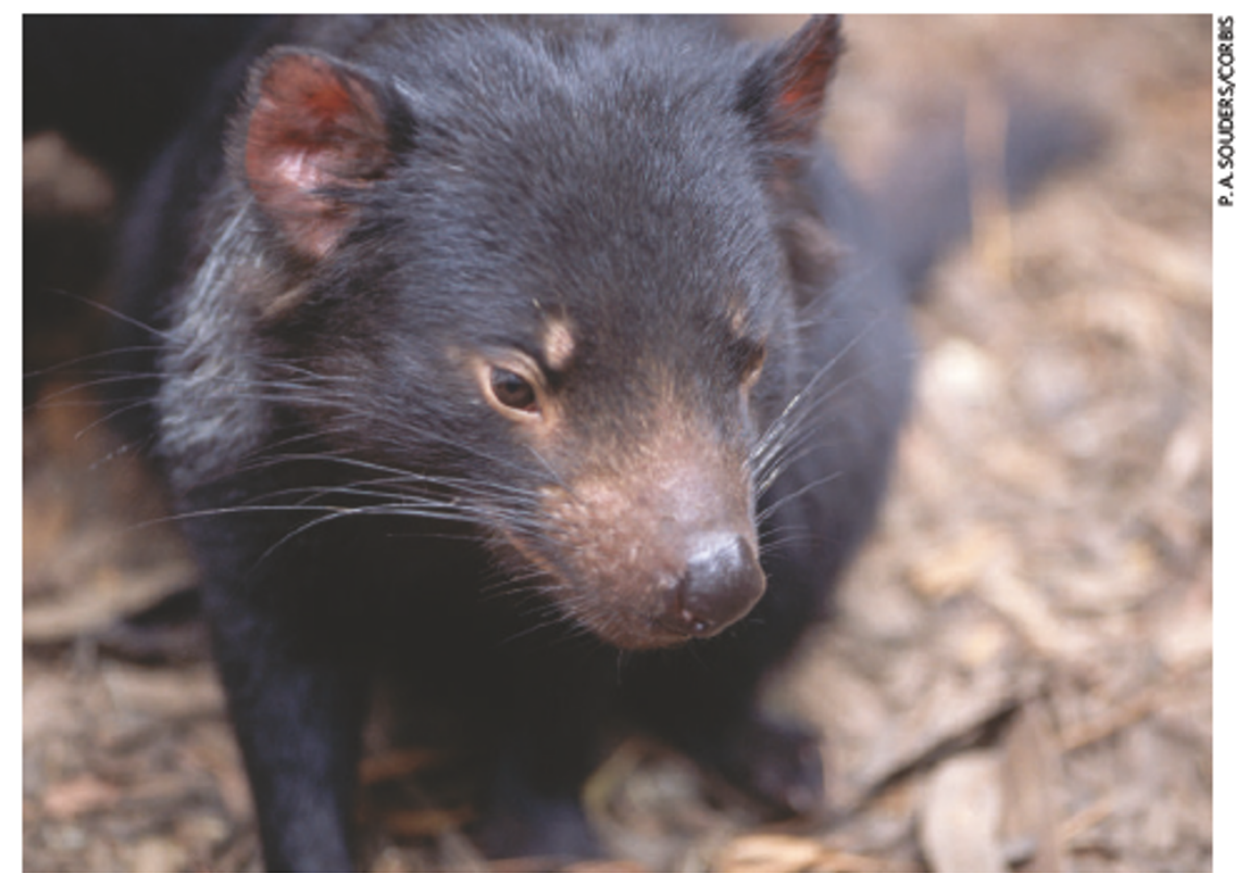

Justmisunderstood? Science has shown that the Tasmanian devil isn't so satanic after all.

menace are appealing. But I wonder whether the use of anecdotal evidence to lay the blame for poultry and trap raiding on the even rarer spotted-tailed quoll (Dasyurus maculatus) only extends the tyranny of prejudice.

Peripheral connections to the devil story provide light relief. Particularly well fleshed out is the link between Theodore Flynn, who studied devil reproductive anatomy, his actor son Errol, who dubbed himself' the Tasmanian devil', and Errol's employer, Warner Brothers, who have profited immensely from Taz cartoons and merchandising.

The inclusion of a wide array of reports and newspaper articles provides the reader with access to a mostly bygone mood of malevolence towards the devil, as well as to the voices that began to change this attitude. It is particularly sad that having survived being shot, poisoned and trapped for bounties, and finally winning considerable public affection, devils are now succumbing to devil facial tumour disease. The authors relate the few clear facts about this hideous affliction, which seems to spread through biting and is devastating devil populations across much of Tasmania. It is unknown whether the disease is an old foe or whether its origins lie elsewhere, for example in the accumulation of anthropogenic carcinogens. At this and other points of uncertainty I was left wondering what the Tasmanian aboriginals could have told us about the devil, had misunderstanding, persecution and disease not led to their own demise.

The authors have succeeded in demystifying the Tasmanian devil and reveal a fascinating creature; we would be much poorer without it. Nevertheless, if you were to follow some raucous screams through the dark Tasmanian night and came upon half a dozen of these stout, black marsupials gorging on the carcass of a cow with their bone-crunching teeth, you might still think they were devils indeed. Matthew J. Phillips is at the Allan Wilson Centre for Molecular Ecology and Evolution, Massey University, Palmerston North, New Zealand. 